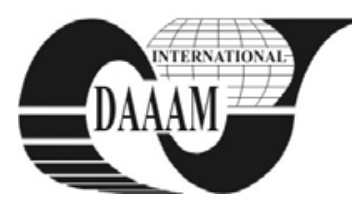

\title{
SPECIFIC FACILITIES PLANS FOR SHIPS TANKER
}

\section{SIVRIU DOINEA, G[eorgiana]; BEJAN, R[amona]; MITU, D[aniela] \& BOCANETE, P[aul]}

\begin{abstract}
The vessel is built to carry freight, passengers or to meet other goals in the conditions of navigation at sea. To achieve these objectives, it is subjected to restrictions imposed by operating conditions. Board naval installations are complex electromechanical systems, with defined roles in boarding and disembarking goods, freezing and storage of perishable goods, providing living conditions for crew members overboard discharge of sewage permeated the ship's compartments, maintaining and ensure the vitality of the vessel both stationary and underway.

Key words: oil tanker, room cargo pumps, slop tanks
\end{abstract}

\section{INTRODUCTION}

Type-specific development plans oil vessels

Regardless of the type of tank it is arranged so as to ensure its structure functional role. In the most general case, a tankertype vessel consists of the following areas: the bow section, center section and aft section, each having its own specificity as follows (Fig. 1):

\section{Oil tanker (side view)}

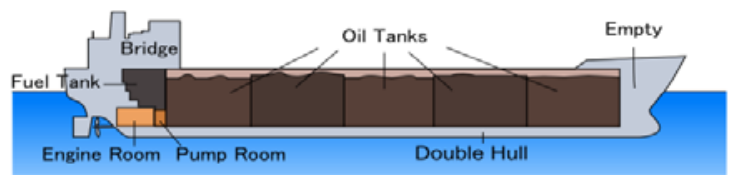

Fig. 1. Overview of a tanker-type ship

\section{PRESENTATION OF THE MAIN SECTION OF A TANKER-TYPE SHIPS}

a) Section bow: it is necessary for ensuring the vessel and navigational services and includes:

- Forward collision tank, closed with a transverse bulkhead aft bulkhead construction and special strength, are behind this wall of bunker tanks and wing void the entire with of the ship from keel to main deck;

- Under the forecastle deck are: storage facilities, pump house and wells bunker transfer chains, and above the maneuvering and mooring winches.

- Jacks may be: with self stowing mooring winch- equipped with a mooring winch drum which is wound a rope is recovered according to the draft Standing ship, the operation varies rapidly, the voltage (tension winch) - self recovery winch fitted

with a device that may be set to continuously adjust the strap tension mooring.

b) Center section is always dedicated cargo tanks and has the largest size. Depending on the destination of the ship, the space is divided into cargo tanks and ballast tanks, including (Fig. 2) :

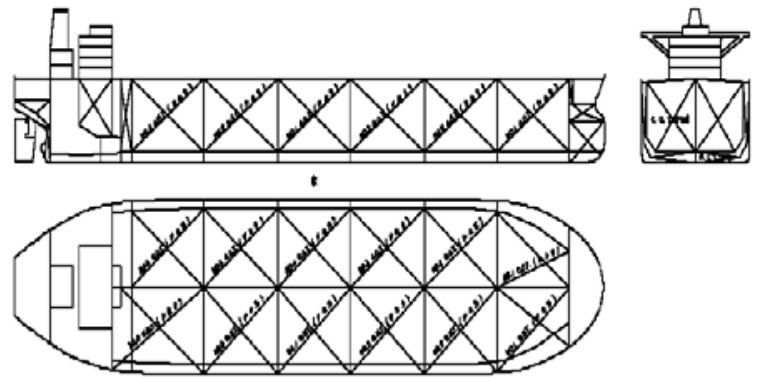

Fig. 2. Central area cargo tank

- Central tanks located inboard of the longitudinal closure;

- Side tanks adjacent to the side of the vessel;

In the area of this section is located aft cargo pump room (room cargo pumps), the ship's structure adjacent compartment from the engine room, they are often placed cargo pumps, strips, etc. ballast.

- Waste tanks (slop tanks) tanks for collecting cargo residues or washing, in which the separation of oil and water pond from which water is removed (usually slop tanks are located close to the pump room freight);

For prevention of marine pollution in ballasting the ballast tanks clean to remove water from slop tanks or bilge water from engine room and pump room, air filtration is provided with a separate monitor spilled oil (oil discharge monitor). It is an instrument used for measuring and recording the remaining hydrocarbon concentration in water overboard repressed (the measurement is made in parts per million, the maximum currently allowed is $15 \mathrm{ppm}$ ).

\section{SPECIFIC ELEMENTS FOR TANKER SHIPS}

All elements in the center meet specific oil type vessels:

- Manifold - from the deck of the vessel in both edges, that is cross-connection between piping flanges terminal lines for cargo loading and unloading operations;

- Lines of pipes through that the main deck cargo handling;

- Valves: Closing-opening valves are fitted with piping to direct the movement of fluids or to adjust the operating parameters of the plant

- Sprouts of vegetation: evidence provided by the site, installed in cargo tanks at the end of the suction pipe of the goods;

- Filters, pipe fittings mounted suction pumps for the retention of foreign bodies and prevent damage to pump. 


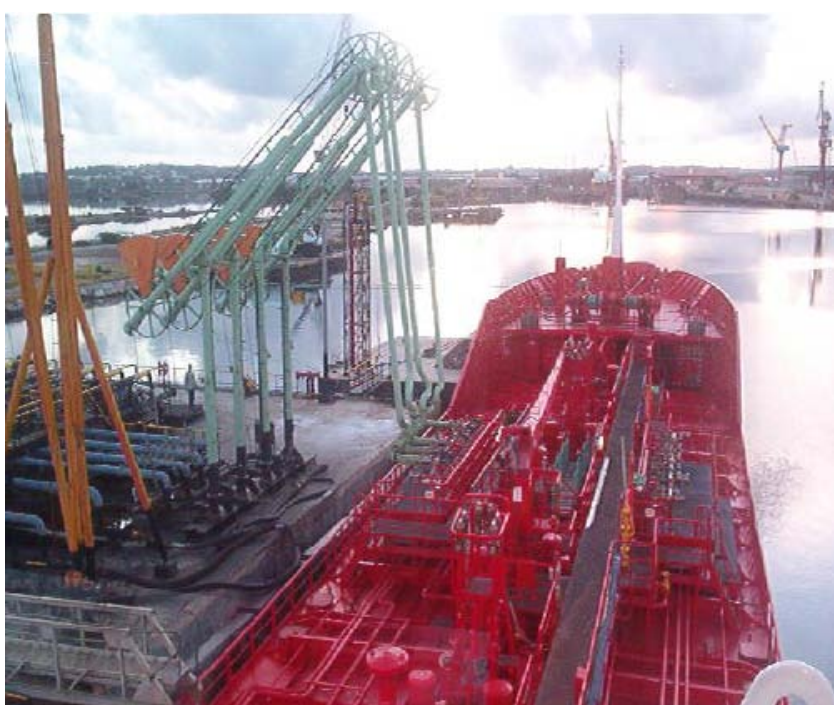

Fig. 3. Petroleum operating with manifolds

c) Section stern: the center section is separated by a transverse wall and is sealed compartment for machines. Above the castle car compartment, and aft ballast tank intended impact of their water supply or technical. Here we find along the ship's facilities and those related to oil.

The manner and degree of separation of cargo tanks is determined by the number of varieties of goods that are intended to be carried simultaneously, and these determine the number of required cargo pumps to be installed.

Cargo facility has the following main elements:

- Cargo pumps - usually a centrifugal pump for discharge of the principally amount of freight cargo tanks (not used for unloading freight remains as it has bad quality and defuse aspiration);

- Striper system - pumping the remaining cargo residues into the cargo tanks, the final part of the discharge, when the probe for measuring oil level in the tank, shows a value of fewer than $1 \mathrm{~m}$;

- Pump strip: it is to be landed last portions of the cargo tank draining and drying (piston pumps are used with very good qualities and does not defuse the suction aspiration of air through the sprouts of vegetation or leaks);

Among the cargo tanks and other compartments to provide vertical and horizontal wing voids. The oil tankers for the transport of flash point below $20^{\circ} \mathrm{C}$, wing voids must exist among the cargo tanks and main engines and auxiliary fuel.

To avoid triggering fires and explosions, all the ancillary facilities of the board cargo tank cars are powered by hydraulic or steam. For the same reason, highly flammable products are distributed in stores in the bow, while those with low degree of flammability in the aft hold.

Loading cargo tank alternative, with oil and sea water accelerates the corrosion of structural elements. In modern tankers this inconvenience has been eliminated by arranging special ballast tank in double bottom and that between the cargo tanks.

The ship has a total of six plants and eight tanks side, that makes it able to theoretically capable of carrying 14 different product types. Each pair of side tanks must carry the same type and same amount of petroleum products, not create problems in loading and unloading and the hull does not substantially different efforts.
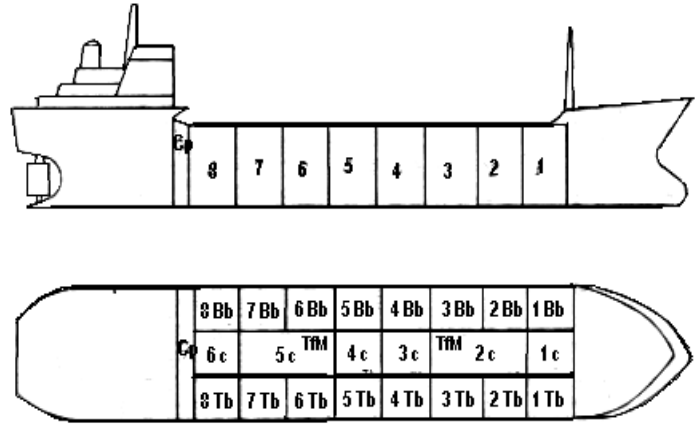

Fig. 4. Arrangement cargo tanks a vessel transporting petroleum products (Cp - pump rooms TFM - cargo tanks high for special cargo shorts)

As shown in Fig.5 a typical vessel for carrying crude oil is provided with a central tank number five and six pairs of wing tanks. Less side tanks are explained by the need to carry an extra amount of ballast during a voyage by ship ballast.
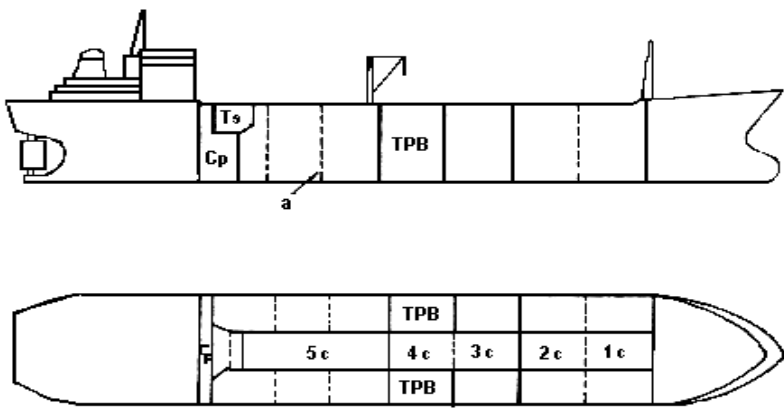

Fig. 5. Cargo tanks layout on a ship oil (A - Transverse bulkhead to reduce free surface effect, Ts - slop tank; Cp-pump rooms TPB - permanent ballast tank)

\section{CONCLUSION}

All new oil tankers are built with modern body double, to eliminate potential risk of environmental pollution arising from any accidental leak in cargo tanks ship.

If modern tankers, cargo space for transport is divided by two longitudinal bulkheads and watertight walls any several of transverse bulkheads in cargo tanks and lateral central Tb-Bd.

\section{REFERENCES}

Baptist C., Captain - „Tanker handbook for deck officers”, Brown, Son \&Ferguson Ltd., Eight Edition, Glasgow, 2000

Comstock J. - Principles of naval architecture, S.N.A.M.E., NJ, 1967;

Bai Y., Marine Structural Design, Houston, USA, 2003;

Bennett A., Ship Fire Prevention The Shipbuilding Research Association - „Study on cargo oil tank corrosion of oil tanker”, Report of Ship Research Panel, Tokyo, 2002

D. J. Eyras Ship Construction, Formerly Lecturer in Naval Architecture Department of Maritime Studies, Plymouth Polytechnic, (now University of Plymouth) 